\title{
Fresh perspectives on TPACK: pre-service teachers' own appraisal of their challenging and confident TPACK areas
}

\author{
Teemu Valtonen $^{1}$ (D) Ulla Leppänen ${ }^{1}$ - Mareena Hyypiä ${ }^{1} \cdot$ Erkko Sointu $^{1}$ • \\ Anneke Smits ${ }^{2} \cdot$ Jo Tondeur ${ }^{3}$
}

Received: 26 August 2019 / Accepted: 20 December 2019 / Published online: 3 January 2020

(C) The Author(s) 2020

\begin{abstract}
The present study is an extension of studies that measure pre-service teachers' Technological Pedagogical Content Knowledge (TPACK) confidence. It provides new perspectives on pre-service teachers' TPACK by shifting the focus to concrete concerns and strengths indicated by pre-service teachers. The target group consists of a cohort of firstyear pre-service teachers $(N=86)$ from a Finnish university. The data used in this study were 86 lesson plans with integrated technology written by first-year pre-service teachers, with a specific section where students outlined their confident and challenging areas in the lesson plan. These sections were analysed quantitatively through the theoretical lens of TPACK. Four TPACK areas were found confident, challenging or both confident and challenging for students. For these first-year pre-service teachers, pedagogical knowledge played the most important role, and the outcomes concretize specific aspects of pedagogical knowledge that can be addressed to develop TPACK in teacher education. The results provide important perspectives on pre-service-teachers' development of TPACK, revealing the important position of pedagogical knowledge and detailed perspectives on how pre-service teachers view their readiness to use ICT in education.
\end{abstract}

Keywords Pre-service teacher - Technological pedagogical content knowledge - TPACK . Qualitative study, lesson plans

\section{Introduction}

New technologies provide several new opportunities for supporting learning. The development of technologies that can be used for education is rapid. The yearly Horizon reports (see. Freeman et al. 2017) predict the development of educational

Teemu Valtonen

Teemu.valtonen@uef.fi

Extended author information available on the last page of the article 
technologies for the coming years, outlining developmental trends in the area. In these reports, we can see the technologies that are expected to be part of everyday teaching and learning practices in $\mathrm{K}-12$ schools within the next five years. Table 1 shows a combination of the predictions for K-12 education from the 2014-2017 Horizon reports, which provide an overview of the development of educational technology and related pedagogies. The technologies that are mentioned in the reports vary from specific technology, such as 3D printing and robotics, to larger development areas, such as Makerspace, and the use of learning analytics that are primarily characterised by pedagogical developments related to technology use. This development in technological and pedagogical areas provides (pre-service) teachers with several new possibilities for different educational purposes. However, new technologies also pose challenges for (pre-service) teachers, demanding new skills and knowledge to take advantage of the new technologies in pedagogically meaningful ways.

Table 1 presents an outline of technologies that can be used for different content areas and for different pedagogical practices. Still, integrating these technologies into everyday teaching and learning practices should not be taken for granted. According to Ertmer (2005), the nature of teachers' pedagogical beliefs is an important part for successful technology integration. In addition, schools' readiness, i.e. support, resources, perceived importance of ICT integration and the sharing of ideas between teachers, is vital for ICT integration (Petko et al. 2018). Similarly, Brinkerhoff (2006) suggested facilitating conditions, support and administration as important factors for integrating ICT in school practices. For pre-service teachers, Teo and Milutinovic (2015) have shown that attitudes towards the use of ICT in education play a crucial role in the intention to use ICT. According to Mishra and Koehler (2006), successful ICT integration depends on teachers' skills to combine knowledge related to technology, pedagogy and content. Altogether, several factors affect successful ICT integration. This complexity forms a partial explanation for the fact that technology integration remains challenging. Tondeur et al. (2012) and Gao et al. (2011) have found that preservice teachers and newly qualified teachers in particular find the use of ICT in education in diverse and flexible ways challenging.

The focus of this research is on pre-service teachers' perceptions of the use of ICT in education from the point of view of the Technological Pedagogical Content Knowledge (TPACK) framework. TPACK is a framework for studying and describing (pre-service) teachers' knowledge related to the pedagogically meaningful use of ICT in education (Mishra and Koehler 2006). This framework combines knowledge of pedagogy, technology and the content taught (TPACK is described in more detail in the next section). The aim of this qualitative study is to highlight the TPACK areas in which first-year pre-service teachers are confident and those they find challenging. The aim of this research is to provide space for the pre-service teachers' personal interpretations and the topics they want to highlight.

\section{Theoretical framework}

This research is grounded on the TPACK framework (Mishra and Koehler 2006). TPACK is a framework for describing and studying (pre-service) teachers' knowledge related to the use of ICT in education. The TPACK framework is based on three 


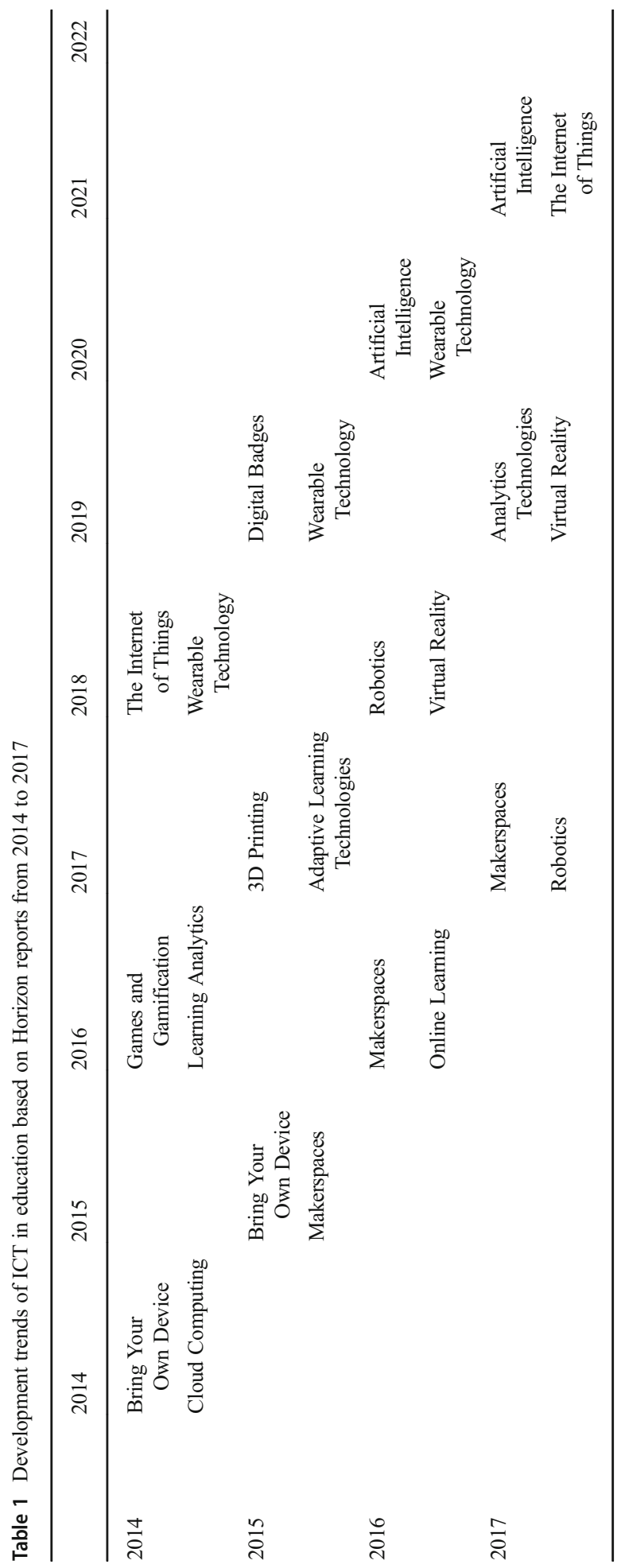


fundamental knowledge areas: technological knowledge (TK), pedagogical knowledge (PK) and content knowledge (CK). In combination, these areas form the following knowledge areas: technological pedagogical knowledge (TPK), pedagogical content knowledge (PCK) and technological content knowledge (TCK) (more detailed descriptions in Tables 2 and 3). The integration of all separate areas produces TPACK, i.e. 'an understanding that emerges from interactions among content, pedagogy, and technology knowledge [...] knowledge underlying truly meaningful and deeply skilled teaching with technology' (Koehler et al. 2013).

The TPACK framework is based on the PCK model by Shulman (1986), who emphasised the importance of combining the areas, i.e. combining PK and CK as PCK. Shulman has defined PCK as a 'special amalgam of content and pedagogy that is uniquely the province of teachers, their own special form of professional understanding' (Shulman 1987, p.8). The addition of TK to the original PCK framework provides us with a larger framework to better examine the role of ICT in education. Since the introduction of the TPACK framework (Mishra and Koehler 2006), it has been actively used in hundreds of studies (Harris et al. 2017). These focus on various topics related to ICT integration with various research methods.

There are several ways to study and assess (pre-service) teachers' TPACK and their confidence in different areas as defined in the TPACK framework (Author et al., 2013; Koehler et al. 2014; Willermark 2018). Several studies have been conducted using quantitative methods in which respondents have assessed their confidence in different TPACK

Table 2 TPACK constructs. Based on articles by Mishra and Koehler (2006) and Chai et al. (2010)

TPACK Description

constructs

CK ...knowledge about the taught subject matter containing knowledge of theories, concepts and practices in the field. CK contain deep knowledge fundamentals of the disciplines without consideration about teaching the topic.

PK ...knowledge of teaching and learning practices, knowledge of classroom management and assessment, knowledge of how students construct knowledge. PK focuses on learning theories in general without focusing on teaching certain contents.

TK ...knowledge of technology, understanding and recognizing the possibilities of technology. TK refers to knowledge needed to adapt the fast development of technology without focusing on teaching and learning.

PCK ...knowledge of transforming the subject matter knowledge for teaching, organise conditions for making the learning of certain contents easy. PCK contain also knowledge of typical misconceptions related to certain topics.

TCK ...knowledge of how technology and content influence one another, knowing the technologies used within different subject matter areas. TCK consists of knowledge how subject matter develop with technology, without considering teaching the content area.

TPK ...knowledge of how to support certain pedagogical approaches with appropriate technology, to know pedagogical benefits and constraints of different technologies. Aligning with TK, TPK refers to forward-looking technology use in order to find best ways to support learning without focusing certain content areas.

TPACK ...knowledge of using various technologies and pedagogical approaches while teaching different contents. Understanding that emerges when combining CK, TK and PK, knowledge underlying skilled teaching with technology. 
Table 3 Frequencies of TPACK areas mentioned

\begin{tabular}{llllll}
\hline Area & Confident & Challenging & Confident and challenging & Total & Not mentioned \\
\hline PK & 12 & 16 & 24 & 52 & 28 \\
TK & 10 & 10 & 2 & 22 & 58 \\
PCK & 9 & 14 & 4 & 27 & 55 \\
TPK & 7 & 39 & 7 & 53 & 27 \\
Altogether & 38 & 79 & 37 & 154 & 168 \\
\hline
\end{tabular}

areas (Archambault and Crippen 2009; Valtonen et al., 2018; Koh et al. 2010). However, the results of these studies are not consistent. Koh et al. (2010) have reported that PK is the TPACK area with the highest confidence scores whereas CK came out as the area with the lowest scores. Chai et al. (2010) also found that PK scores were the highest and that TK were the lowest scores. In line with these findings, Archambault and Crippen (2009) have reported that PK is the highest-scoring area; however, they also reported the conflicting finding that TK is one of the strong areas, together with TK and PCK. Valtonen et al. (2018) reported strong outcomes for PK and CK in first-year pre-service teachers' self-assessments. Partly aligning with these findings, Baran et al. (2011) reported that CK and TPK showed the highest scores among pre-service teachers. Taken together, these results paint a rather complex and partly contradictory picture of pre-service teachers' development of TPACK. Common to all the studies above was that differences between TPACK elements were small. Another common feature was that PK was a TPACK area in which teachers have the highest confidence in several studies.

TPACK has been studied and measured using qualitative methods. In several review studies, these methods have been categorised as performance assessment (Archambault 2016; Fisser et al., 2015, Koehler et al. 2014; Willermark 2018). What is common for these methods is that (pre-service) teachers' TPACK is studied and assessed based on different artefacts, such as lesson plans, actual teaching periods or other design tasks or cases (Archambault 2016). In these studies, the TPACK framework has served as a theoretical background for reflection on the artefacts that were produced by the students. According to Harris et al. (2010), the production of artefacts, such as lesson plans, provides a pragmatic window into teachers' development of TPACK. Compared to survey studies, studies with performance assessment methods provide deeper insight into the nature of pre-service teachers' TPACK.

According to Sadaf et al. (2012), today's pre-service teachers have rather positive attitudes towards the use of ICT in education. Nevertheless, challenges are encountered in pre-service teachers' readiness to integrate ICT into education (Valtonen, 2011; Lei 2009). Thus, we set out to gain more knowledge of pre-service teachers' TPACK, using qualitative analysis. The aim is to use pre-service teachers' own written expressions of their confident and challenging TPACK areas.

\subsection{Purpose of the study}

The purpose of the study is to chart pre-service teachers' TPACK based on their own descriptions of TPACK areas in which they are confident and areas that they 
find challenging. This study creates a picture of TPACK contents using the TPACK areas that pre-service teachers highlight and the areas they indicate worth considering. In TPACK studies using quantitative approaches, the freedom of respondents to explicate their knowledge is limited (Tondeur et al., 2013). In more qualitative studies using performance-based activities (see Archambault 2016; Willermark 2018) the areas of interest within TPACK, are typically pre-defined by researchers. The aim of the present research is to shift the focus to the pre-service teachers' personal interpretations, to provide pre-service teachers with more freedom to express and highlight the topics related to TPACK that they identify as important. We assume that using this approach, we can gain new perspectives on pre-service teachers' TPACK at a more concrete level.

\section{Methods}

\subsection{Participants and research materials}

The target group consisted of a cohort of first-year pre-service teachers $(N=86)$ from a Finnish university. Most of the respondents were female (female $n=69$; male $n=17$ ), which represents the general gender distribution of Finnish pre-service teacher education. Respondents were expected to graduate as primary school teachers, grades 1 to 6 (pupils aged 7 to 13). Teacher education in Finland takes five years, and it consists of a bachelor of arts (Education) degree (180 ECTS) and a master of arts (Education) degree (120 ECTS). The target group of this research consists of first year pre-service teachers, providing insights into the very early phase of the developing TPACK, also known as the proto-TPACK framework (Kontkanen et al. 2016) i.e. evolving TPACK framework based mainly on pre-service teachers' previous personal school experiences.

The data in this study consist of lesson plans written by pre-service teachers. These lesson plans were part of a mandatory course at the beginning of the teacher education program. Pre-service teachers were not obliged to take part in the study. Two preservice teachers did not grant permission to use their lesson plan for research purposes. Consequently, their lesson plans were not analysed. In their lesson plans, pre-service teachers were asked to consider the following areas: (1) the content of the lesson; (2) the grade level (grades 1 to 6); (5) what happens during the lesson and why; (3) what technologies are used; (4) the purpose of using technologies; (6) what would be challenging and easy areas for them as teachers. Pre-service teachers were to challenge themselves with their lesson plan. The lessons they designed were to be challenging for them to enact in actual practice, but not impossible.

The data for this research consist of the part 6 of the lesson plans, i.e. descriptions of easy and difficult areas of the lessons. Other areas of the lesson plans are briefly outlined in the beginning of the results section to provide an overview of the characteristics of the lesson designs. The reasons for this are twofold: (a) while writing the lesson plan, preservice teachers have to use their TPACK by choosing the content of the lesson, pedagogical practices and technologies and ways that these areas support each other. Writing the lesson plans was intended to activate pre-service teachers' thinking and to serve as a context and trigger for their reflective thinking; (b) writing the lesson plan served to encourage pre-service teachers to outline concrete areas that they found easy or 
challenging, by pinpointing practices with ICT in their classes in which they were confident or lacked confidence. In the data-collection phase and in the guidelines for lesson plans, TPACK was not mentioned, i.e. the respondents were able to highlight any areas related to the lesson they chose. Typical for TPACK research is that researchers define the areas measured, the contents of inquiry. In line with Tondeur et al. (2013), the aim of the current method is to provide pre-service teachers with the freedom to express their own ideas, to bring up aspects of TPACK from their own practical perspective and to open the black box of their thinking about technology integration.

\subsection{Data analysis}

A qualitative analysis was performed supplemented with a quantitative analysis of the outcomes. Theory-guided content analysis (see Gibbs 2007; Elo and Kyngäs 2008; Savenye and Robinson 2005) was used for categorising the raw data in line with the TPACK framework to identify the topics in which pre-service teachers felt confident or challenged. Quantitative methods were used to study the frequencies of the different categories that resulted from the theory-guided content analysis. The analysis took place in four phases. The first phase was the theory-guided content analysis. The parts of the lesson plans that dealt with areas in which the teachers felt confident and challenged were coded in line with the TPACK framework. This phase led to 154 codes (see Fig. 1). In the second phase, these codes were categorised in line with areas of TPACK separately for confident and challenged codes. The codes covered four TPACK areas out of seven (PK, TK, PCK and TPK). The third phase of the analysis focused on defining sub-categories for PK, TK, PCK and TPK, providing more detailed insights into these areas. For example, PK (confident) sub-categories were: Supporting pupils' learning process and discussions and Starting the lesson: explaining tasks. The coding and building of categories and sub-categories were conducted using ATLAS.ti version 8.0. The length of units of analysis varied from sentence statements to longer

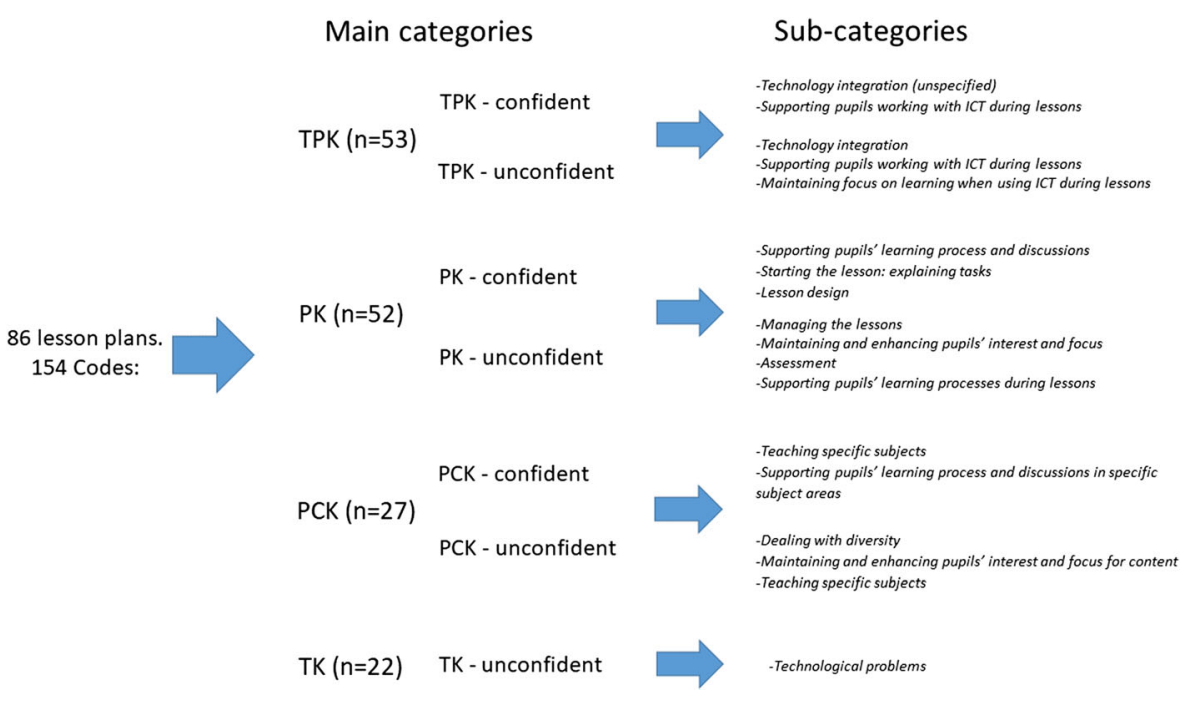

Fig. 1 Data analysis 
units with several sentences. According to Graham (2011), the boundaries of TPACK areas are fuzzy, indicating that the borders are not necessarily distinct. This makes the qualitative analysis challenging for defining the contents for categories close to one another. After the qualitative analysis, the data were exported to Excel to establish the frequencies for the four resulting TPACK areas, for both confident and challenged areas. Sub-categories were counted based on the upper-level categories: PK, TK, PCK or TPK. These results were reported in two tables to outline the frequencies of each area as strong, weak or both.

The research data were analysed by three authors of this paper to triangulate the results with multiple analysts (see Patton 1999). In the first phase, two of the authors read the data together, discussed the TPACK areas and made the first draft of the coding. In the second phase, the third author of this paper coded the data, leading to PK, TK, PCK and TPK codes. The contents of the analysed areas were similar to the first round of analysis, and consensus was achieved. The aims of the three researchers were to avoid selective perception and interpretive bias (Patton 1999) and to avoid the effects of pre-conceptions and expectations of the results.

\subsection{Overview of the lesson plans}

To provide an overview of the lesson plans, this section briefly outlines the basic characteristics of the lessons designed from the perspective of the pedagogy, content and technologies used and the target groups for the lessons. The lesson plans were similar to each other from a pedagogical point of view. All the lessons were grounded in the pupils' active role, i.e. none of the lessons was limited to lecturing. Learning practices focused mainly on working in pairs or in small groups. Most lesson plans $(N=39)$ were designed to emphasise collaborative activities, i.e. pupils working in pairs or in small groups, or the whole class would be creating something together. In 27 lesson plans, both collaborative and independent learning practices were used, i.e. pupils were to work by themselves as well as in pairs or small groups. Fifteen lesson plans mentioned pupils working alone on assignments. In five lesson plans, grouping (group, pairs, alone) was not clearly stated. Lessons were typically designed as projects or larger assignments. The most popular topics for the lessons were Finnish language and literature $(N=31)$ and natural sciences $(n=30)$. The next most popular subjects were arts $(N=7)$ and history and social studies $(\mathrm{N}=7)$. The remaining lesson plans concerned physical education, English language and literature, mathematics, religion, music, health education, handicrafts and Russian language and literature. Some of the planned lessons integrated content from various subject areas, such as Finnish language and arts or natural sciences and history. Lesson plans were mainly developed for fifth $(N=29)$ and sixth grades $(N=27)$. Twelve lesson plans were for fourth grade, and 10 plans were for third grade. Plans for first and second grades only played a minor role. From the perspective of technology, the lesson plans mainly focused on technologies that pupils would use: computers, tablets or pupils' own phones. The Internet was mentioned at a general level as a source for information, pictures, materials etc. Additionally, cloud services were mentioned as platforms for the pupils to work on and to save and share their work. For teachers, the use of interactive white boards, a document camera and a projector for presenting contents/instructions/pupils' products were mentioned. In a minority of lesson plans, the exact websites or applications that 
the pupils were to focus on were mentioned, e.g. Kahoot!, Book Creator, Roll \& Rock and Ekapeli. Pupils were also to use word processing software, such as Microsoft Word, or to create slideshows in Microsoft PowerPoint.

\section{Results}

The TPACK areas in which the pre-service teachers felt confident are outlined first in this section. Then, the challenging areas are discussed. At the end of this section, the frequencies of confident and challenging areas are discussed to provide an overview of the TPACK areas that triggered pre-service teachers' thinking.

\subsection{Confidence in PK}

The TPACK area in which pre-service teachers felt most confident was PK. The PK category contains three sub-categories. The largest PK sub-category was Supporting pupils' learning process and discussions. Within this category, pre-service teachers indicated that they would feel confident in guiding and helping pupils during lessons. This confidence refers to their perceived skills in supporting pupils in their learning process and helping pupils with different activities. The pre-service teachers also felt confident about their skills in conducting conversations and helping all pupils actively participate in lessons. Preservice teachers indicated confidence in their skills in motivating pupils, stimulating pupils' interest in learning activities conducted during lessons. Within this sub-category, there were also several areas of confidence that related to supporting pupils' learning process that were only mentioned once or twice. Examples of these were dividing pupils into groups, supporting pupils' independent learning and assessment.

The easiest area would be supporting pupils' learning process because a teacher can easily help pupils with solving problems and collecting information. (P38).

The easiest thing would be motivating and inspiring pupils to work because this is a natural thing for me. (P8).

Probably conversations with pupils would be the easiest area for me. (75).

The lesson would be easy to implement because the teacher can give the pupils a lot of responsibility when creating materials. The teacher can step back and observe pupils' collaborative skills and other areas. (P77).

The second PK sub-area was Starting the lesson: Explaining tasks. This area consisted of introducing pupils to the learning activities conducted during class. Respondents felt confident with starting the learning process with easy to understand guidelines and instructions for the different learning activities used. Within this category, pre-service teachers referred to starting one separate lesson and to launching a larger project.

I feel that my strong area would be in explaining the rules of the game for pupils if they have not played the game before. (P1). 
Introducing the assignment in a way that it is easy to understand and supervising the work at different phases of the lessons would be easy for me. (25).

The easiest part would be starting the lesson without the use of any technology. (P35).

The smallest PK sub-area was Lesson design. Pre-service teachers indicated confidence in designing and building backgrounds for their lessons. This included choosing teaching and learning practices, how the lesson would proceed and coming up with creative ways of working during the lesson. Some respondents indicated that imagination is the strength they use to come up with different activities and tasks for pupils.

The easiest part would be starting to think about and plan the lesson. (P65).

I think the easy part for me would probably be coming up with different teaching methods. (P34).

My strong area would be the use of my imagination, so I have plenty of ideas for pupils' work and learning. (P47).

The PCK category showed strong similarities with PK. The main difference between these categories was that the pre-service teachers stated confidence in teaching a specific topic, whereas PK confidence was focused more on managing specific pedagogical approaches. PCK can roughly be divided into two subcategories. The first sub-category refers to pre-service teachers' Teaching specific subjects related to the familiarity of the chosen topic for the respondents. The respondents had typically taught the topic when working in schools prior to teacher education, or the topic was familiar to them via their hobbies. This gave pre-service teachers confidence in teaching the topic again.

-Altogether, teaching physical education lessons would be natural for me compared to other subjects at this time of my studies because of my previous experience as a swim coach. (P10).

-I have worked as a substitute teacher in first-grade reading, so for me, working with the alphabet would work out fine. (P35).

The second sub-category of PCK was Supporting pupils' learning process and discussions in specific subject areas. Again, these areas were closely related to PK areas. The difference was the focus on the content area, i.e. respondents were confident that they would be able to make the topic interesting for pupils. Respondents indicated that they were confident in supporting the different learning activities during classes that focused on topics they had chosen.

-During the lessons, I would be able to guide and inspire pupils to learn about news. (P20). 
-...because for those topics, it would be easy to come up with illustrative examples and assignments. (P22).

The PCK category contained responses that could have also been categorised with the $\mathrm{CK}$ category, i.e. statements that refer only to confidence in certain topic areas. There were only a few statements of this type, all in the context of a lesson, so the statements were added as part of the PCK category.

\subsection{Confidence in TPK}

The biggest TPK confidence sub-category was Technology integration (unspecified), which refers to statements indicating that these respondents felt confident in integrating ICT into lessons without more detailed specifications about what technology they would use or for what purposes. The second sub-category, Supporting pupils working with ICT during lessons, indicates pre-service teachers' confidence in providing help and support for pupils' ICT use. This refers to their perceived skills in providing instructions for how to use specific applications and software and to their perceived skills in supporting pupils when working with different technologies. A few respondents showed confidence in producing learning materials with technology and building learning environments.

I think implementing the lesson with technology would be a rather easy task for me. (P48).

I would be able to guide pupils who work with iPads because it is a familiar tool for me. (P72).

Producing a Kahoot game would be easy for me; also, I do not find the use of computers and video projectors difficult. (P70).

The TPK category contains references that could also have been categorised as TK, i.e. statements referring only to confidence in using technology. There were only a few mentions of this, and they were all within the context of lesson plans. For this reason, the responses were embedded into TPK.

\subsection{Challenges in PK}

Challenges in the area of PK can be divided into four sub-categories. The biggest PK sub-category was Managing lessons. Within this category, the time management during lessons was indicated several times. This pertains to pre-service teachers' worries about the amount of time required by different activities and assignments during lessons. They also worried about the amount of time different problem situations, i.e. unexpected situations, would take. This sub-category also pertains to managing a lesson, ensuring that pupils' learning activities proceed as planned and that different assignments are completed, especially within longer learning processes.

The challenging part would be time management. It is difficult to know how much time it takes for pupils to carry out different tasks. (P34). 
The challenging part would be controlling the practical work of groups; working in small groups always creates commotion and challenges. (P21).

The challenge is that the project contains many elements. It would be easy if pupils could just make small presentations based on their books. (P38).

The second PK sub-category was Maintaining and enhancing pupils' interest and focus, focusing on the ability to maintain the lesson as interesting without distractions. Within this category, respondents focused on worries about how they would act during lessons and choose assignments so that pupils' motivation would remain high throughout the lessons and different learning activities.

The challenging part for me would be maintaining pupils' interest in lesson assignments. (P53).

... there are always pupils who are not interested in studying at all. (P48).

The sub-category Assessment indicates respondents' doubts concerning the use of learning activities emphasizing mainly collaborative learning practices and pupils' active role. Respondents had doubts about their skills in assessing pupils' learning from lessons based on different kinds of learning activities and group assignments, i.e. how to assess learning during different learning activities, how to take into account different contributions of different pupils.

The assessments of individual pupils within a project like this would be challenging because the more active pupils may take a bigger role and more responsibility in the process, and pupils who are not interested may not participate in learning activities. (P71).

Assessment demands a lot of observation, and it may be challenging to conduct decent assessments of all pupils. (P77).

The sub-category Supporting pupils' learning processes during lessons consisted of several different responses about challenging areas during lessons. The main concern focused on how to provide pupils with proper feedback for their work during lessons to support the learning process. In addition, within this category several challenges were mentioned only once or twice. These challenges were related to guiding pupils' thinking and conversation in ways that support the learning processes, noticing pupils' needs for support and help and managing problem situations. This category also contains responses concerning how to treat pupils equally and how to define small groups for working.

It would be challenging to provide feedback on texts because you have to remember to be fair to everyone and remember the importance of positive feedback. (P18).

It would be difficult to help pupils that do not ask for help. (P28).

For me, it would be challenging to equally provide pupils with help and support. (p62). 
The most difficult thing would be the composition of small groups, who you can put into the same group. (p63).

\subsection{Challenges concerning PCK}

Challenging areas within PCK could divided into three sub-categories. The first subcategory, Dealing with diversity, concerns pupils' different starting levels in relation to the content knowledge. Respondents were worried about their skills to meet the needs of pupils with different levels of readiness for learning specific content. This challenge was related to designing and developing suitable tasks and assignments for different pupils and producing learning materials for pupils with different needs. Within this subcategory, there were also responses concerning the areas of special education: how to support pupils with special learning needs.

Defining the suitable level of texts would be challenging because pupils' readiness for comprehending different texts may vary a lot. (P19).

Pupils may find it frustrating if assignments are too easy, or too difficult. (P31).

The second challenging PCK sub-category was Maintaining and enhancing pupils' interest in and focus on content. This is closely related to the motivating category in PK. The difference is that, within this category, the responses focused on motivating pupils for certain topics, i.e. how to make the learning of certain content motivating and interesting for pupils. The expressed concerns were related to cases in which pre-service teachers assumed that pupils were not interested in the content area.

I think the most difficult thing in this assignment would be motivating pupils to study the original text. (P19).

Again, the challenge will be, can I make all the pupils listen and participate, despite that I think the topic is interesting enough? (P75).

The third PCK sub-category was simply Teaching specific subjects. These responses were focused on difficulties in making pupils understand a topic. There were several short responses about such difficulties without more detailed descriptions of the reasons this would make teaching a specific topic challenging.

As a teacher, I would need to explain the content area very well, which I think would be challenging, causing difficulties. (P72).

\subsection{Challenges concerning TPK}

Within TPK, the biggest sub-category, Technology integration, entailed low confidence in the use of ICT during lessons. These responses were typically 
short and focused on certain specific technologies, such as SMART Boards or Office 365. These responses emphasized the role of SMART Boards. Respondents expressed concerns at a very general level, i.e. that the use of ICT would be challenging without any further details. There were also a few responses that focused on general technology skills, i.e. that could have also been categorised as TK. Nevertheless, all the responses were in the context of the lesson, and for this reason, they were categorised as TPK.

The most challenging part for me would be the diverse use of technology, to be able to cope with different applications and tools. (P46).

For me, the use of SMART Boards would be difficult. (P3).

The second TPK sub-category was Supporting pupils working with ICT during lessons. Responses revealed concerns about readiness to help pupils in their work with ICT to provide support. In addition, there were concerns about recognizing pupils' skills and readiness to use ICT. This concern is related to the area of PCK Dealing with diversity, i.e. knowing pupils' level for learning a certain topic, the difference here was readiness and skills in using technology.

As a teacher, I would find it challenging to help pupils use applications, when pupils find them difficult to use. (P79).

Organizing the lessons when using iPads would be difficult, especially when pupils are not already familiar with iPads. (P87).

The last sub-category in TPK was Maintaining focus on learning when using ICT during lessons. Respondents were worried about their skills in controlling lessons so that computers would only be used for the right purposes, for supporting learning and not for games or other entertainment use on the Internet. This area also focused on concerns about how to stay in control during lessons with ICT. The assumption was that use of ICT might cause disruptive behaviour during lessons.

How I can make pupils do certain assignments, to concentrate on a specific application, because the iPad provides several other tempting possibilities. (P35).

The challenge would be in using iPads so that pupils remain on the right page where they can find information related to the learning tasks and not start surfing to other pages or playing games. (P72).

\subsection{Challenges concerning TK}

Only one sub-category was identified for TK. Responses in this category focused singularly on technical problems and skills in solving these problems. TK challenges 
were formulated outside the learning context and indicated general technological difficulties or problems without specification of certain technology or application.

The use of technology worries me a bit, if applications do not work, or if there are difficulties with different software. (P42).

In addition, the technical problems that probably would surface with this amount of technology would be challenging. (P46).

\subsection{Frequencies of confident and challenging areas}

The following step of the analysis identified the frequencies of confident and challenging TPACK areas (see Fig. 2). Frequency refers to how many respondents mentioned a specific TPACK area, i.e. one respondent may have mentioned one TPACK area several times, but in this figure all the responses are counted as one. The results indicate that the two TPACK categories that were mentioned most often were TPK, mentioned by 53 respondents, and PK, mentioned by 52 respondents. PK was mentioned as a challenging area by 16 respondents, as an area of confidence by 12 respondents and as both a challenging and confident area by 24 respondents. As such, PK showed the largest variation among respondents. The situation was different for TPK. Most respondents $(n=39)$ mentioned TPK as a challenging area. Only seven indicated TPK as an area of confidence or as both challenging and confident. The fewest responses involved TK ( 22 respondents).

A comparison of differences between areas indicates an emphasis on weak TPACK areas. Altogether weak areas were mentioned in 79 lesson plans, strong areas were mentioned in 38 lesson plans and 37 lesson plans contained both strong and weak areas. In a comparison of all areas, PK stands out with the largest number of respondents that indicated areas of confidence and areas that were challenging.

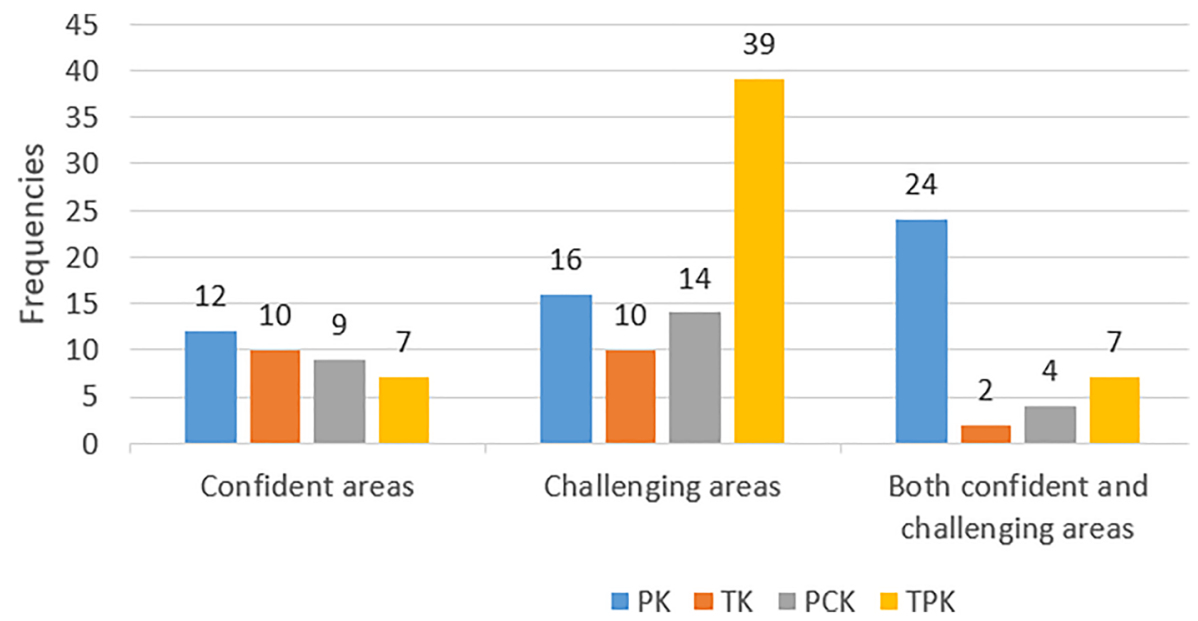

Fig. 2 Frequencies of TPACK areas 


\section{Discussion}

The aim of this article was to provide an overview of pre-service teachers' TPACK, the areas in which they felt confident and those they found challenging, and especially, the areas they highlight. The results indicate that PK, TK, PCK and TPK were the TPACK areas that respondents indicated as areas of confidence or areas that were challenging. TPK and PK were the most frequently mentioned areas. TPACK areas not mentioned were CK, TCK and TPACK itself. Responses were typically specific, focusing on rather narrow areas instead of actual TPACK combining all three fundamental knowledge areas. This research indicate the central role of pedagogical knowledge in pre-service teachers developing TPACK. The role of PK is a TPACK area that has been identified as both an area of confidence and a challenging area, even by the same respondent. PK is an area that triggers pre-service teachers' thinking; other areas like technology play a minor role. We see this as important, reflecting the starting point for the development of TPACK, or ProtoTPACK (see. Kontkanen et al. 2016). In addition, differences can be identified between responses concerning PK and responses concerning TPK. Typically, responses that pertained to PK contained several different perspectives and were open in a more detailed manner than responses that pertained to TPK. Responses pertaining to technology were typically shorter. We assume these results, again, indicated the important role of PK in pre-service teachers' TPACK. PK is the area that pre-service teachers acknowledge best and are able to reflect on, the core of developing TPACK. The results also show that, altogether, pre-service teachers suggest more areas in which they were less confident than areas in which they were confident. In addition, in terms of the frequencies of the TPACK areas, TPK peaks in the challenging area more than other TPACK areas. This finding is in line with results of previous studies that indicate that pre-service teachers have difficulties in using ICT in diverse and flexible ways (Lei 2009).

Based on previous TPACK studies, the TCK has typically been the most challenging area (Archambault and Crippen 2009; Author et al., 2018; Koh et al. 2010). It is remarkable that this area is not mentioned by the first-year students. Our assumption is that first-year pre-service teachers lack the knowledge to consider these topics, i.e. content-specific affordances of technologies, when designing lessons. What is also important is the absence of responses concerning content knowledge. In their lesson plans, the students dealt with $\mathrm{CK}$ as a part of PCK. We assume that this originated in the instructions for the lesson plans. Furthermore, when pre-service teachers were allowed to choose the topic for their lesson, they selected a topic that would not cause them difficulties or that would be familiar to them. The results might have been different if the content had been pre-defined.

\subsection{It's about pedagogy: About practice}

The results of this study show the important position of PK. Pedagogical areas show both confidence and worries. In our data, areas related to pedagogy, especially PK and TPK, are the areas of concern most often highlighted by the first-year pre-service teachers. In addition, the students were able to make explicit which concrete aspects of PK they were concerned about. 
Many previous studies conducted using quantitative methods have emphasized the role of PK as one of the most confident areas (see Archambault and Crippen 2009; Author et al., 2018; Koh et al. 2010). Compared to these results, the present findings can be seen as in agreement and as conflicting. The PK areas were not only identified as confident, but also as challenging or as both confident and challenging. These results suggest that PK is the TPACK area that triggers respondents' thinking most. The responses in areas related to pedagogy contained many different topics from both challenging and confident perspectives that were described in a more detailed way than the responses in the other TPACK areas. We assume that the results from previous quantitative studies and from the present study are an expression of the same phenomenon, i.e. the important role of pedagogy in pre-service teachers' developing TPACK. In addition, the present study allowed students to inspect that area in more detail and to identify challenging and confident details. These details provide teacher educators with concrete and practical topics and discussion points to help students to develop their TPACK.

The results also indicate the importance of providing respondents with more space to express their opinions related to TPACK. Author et al. (2013) have used the stimulated recall approach to gain new knowledge and understandings of the black box, i.e. the complexities of ICT integration. The aim of that study was to provide respondents with more freedom to explain areas related to ICT integration in their own words. Similar to the present study, the results provided us with more practical perspectives on areas that pre-service teachers consider themselves as confident or un-confident. Instead of mainly considering the ICT skills of pre-service teachers, the challenges may arise from the effects that the use of ICT applications with access to the Internet can have for classroom management. Similarly, the use of collaborative learning practices and projects with ICT can trigger questions about assessment, time management and control over the classroom. The diversity of pupils either based on their CK or ICT skills also led to questions. This type of detailed and practical perspective must be studied to understand the nature of pre-service teachers' developing TPACK and identify the bottlenecks that may inhibit pedagogically meaningful ICT integration. By identifying areas of concern for pre-service teachers, and interpreting them in terms of TPACK, content can be developed for methods that serve to overcome the challenges that are indicated. Confident and challenging areas can be considered a way to trigger preservice teachers' reflective thinking and to concretize the TPACK framework for preservice teachers.

\subsection{Limitations and future studies}

The results provide an overview of pre-service teachers' perceptions of their weak and strong TPACK areas. From the perspective of qualitative content analysis, the TPACK framework has its benefits and challenges. As a flexible framework, it is well suited for various research purposes; nevertheless, the TPACK framework with seven areas causes challenges. According to Graham (2011), the boundaries of TPACK elements are fuzzy, and the areas are close to each other. This caused difficulties with analysing the qualitative data based on the TPACK framework. However, the analysis with quotation examples still ended with well-justified categorisation. The final categorisation was comprised of four TPACK areas. Further categorising of the data, for example, to extract CK as separate from PCK, or TK 
separate from TPK could have been done. However, we found the categorisation used in the present study more appropriate. The number of separate CK or TK categories would have been minimal, and yet they would have been in the context of lesson plans, i.e. in a pedagogical context.

Despite these difficulties, the current study provides new, important perspectives for TPACK research, from which several new research angles can be derived. Within this study, pre-service teachers were provided with considerable freedom in designing lessons. In the future, the same method should be used with more pre-defined content and/or technology. The role of CK was minor in our findings. We assume that deeper insights into the development of pre-service teachers' TPACK can be gained by assigning the content, for example, teach the concept of atmosphere to fifth-grade elementary school pupils. We assume that this kind of change would trigger different types of thinking and would provide new perspectives for developing TPACK.

Based on previous studies, the role of PK is important for the development of other TPACK areas (Chai et al. 2010; Pamuk 2011). The results of the present study show that PK is the core of the developing TPACK. From this perspective, we assume that the use of PK should be considered as an area for developing pre-service teachers' TPACK in line with Chai et al. (2010) and Pamuk (2011). Several concrete challenges were indicated within the PK area, providing a good starting point for different activities for developing pre-service teachers' TPACK areas.

\section{Conclusion}

The present study is an extension of studies that measure pre-service teachers' TPACK confidence. It provided new and important perspectives by shifting the focus to concerns and strengths indicated and highlighted by pre-service teachers at a concrete level. The results provide important perspectives on pre-service-teachers' development of TPACK, revealing the important position of PK and more detailed perspectives on how pre-service teachers view their readiness to use ICT in education. Based on previous studies, we know that today's pre-service teachers have positive attitudes toward the use of ICT in education; however, integrating ICT remains challenging. We assume these more personal and concrete perspectives on challenges and strengths provide important knowledge for teacher education that must be acknowledged to support the development of pre-service teachers' use of ICT in education to help them cope with the fast-developing field of ICT in education.

Acknowledgements Open access funding provided by University of Eastern Finland (UEF) including Kuopio University Hospital. This work was supported by Academy of Finland [project number 296799].

\footnotetext{
Open Access This article is licensed under a Creative Commons Attribution 4.0 International License, which permits use, sharing, adaptation, distribution and reproduction in any medium or format, as long as you give appropriate credit to the original author(s) and the source, provide a link to the Creative Commons licence, and indicate if changes were made. The images or other third party material in this article are included in the article's Creative Commons licence, unless indicated otherwise in a credit line to the material. If material is not included in the article's Creative Commons licence and your intended use is not permitted by statutory regulation or exceeds the permitted use, you will need to obtain permission directly from the copyright holder. To view a copy of this licence, visit http://creativecommons.org/licenses/by/4.0/.
} 


\section{References}

Archambault, L., \& Crippen, K. (2009). Examining TPACK among K-12 online distance educators in the United States. Contemporary Issues in Technology and Teacher Education, 9(1), 71-88.

Archambault, L. (2016). Exploring the use of qualitative methods to examine TPACK. In. M. Herring, M. Koehler, \& P. Mishra, (Eds.), Handbook of technological pedagogical content knowledge (TPACK) for educators (pp. 6586). Routledge.

Baran, E., Chuang, H. H., \& Thompson, A. (2011). TPACK: An emerging research and development tool for teacher educators. Turkish Online Journal of Educational Technology-TOJET, 10(4), 370-377.

Brinkerhoff, J. (2006). Effects of a long-duration, professional development academy on technology skills, computer self-efficacy, and technology integration beliefs and practices. Journal of Research on Computing in Education, 39(1). https://doi.org/10.1080/15391523.2006.10782471.

Chai, C., Koh, J., \& Tsai, C.-C. (2010). Facilitating preservice teachers' development of technological, pedagogical, and content knowledge (TPACK). Educational Technology \& Society, 13(4), 63-73.

Elo, S., \& Kyngäs, S. H. (2008). The qualitative content analysis process. Journal of Advanced Nursing, 62(1), 107-115. https://doi.org/10.1111/j.1365-2648.2007.04569.x.

Ertmer, P. A. (2005). Teacher pedagogical beliefs: The final frontier in our quest for technology integration?. Educational technology research and development, 53(4), 25-39.

Fisser, P., Voogt, J., van Braak, J., Tondeur, J., \& Spector, J. M. (2015). Measuring and Assessing TPACK (technological, pedagogical content knowledge). The SAGE Encyclopedia of Educational Technology.Vol. 2, 490-493.

Freeman, A., Adams Becker, S., Cummins, M., Davis, A., \& Hall Giesinger, C. (2017). NMC/CoSN horizon report: 2017 K-12 edition. Austin, Texas: The New Media Consortium.

Gao, P., Chee, T. S., Wang, L., Wong, A., \& Choy, D. (2011). Self-reflection and pre-service teachers' technological pedagogical knowledge: Promoting earlier adoption of student-centred pedagogies. Australasian Journal of Educational Technology, 27(6), 997-1013. https://doi.org/10.14742/ajet.925.

Graham, C. R. (2011). Theoretical considerations for understanding technological pedagogical content knowledge (TPACK). Computers \& Education, 57(3), 1953-1960.

Gibbs, G. (2007). Analyzing qualitative data. London: Sage Publications.

Harris, J., Phillips, M., Koehler, M., \& Rosenberg, J. (2017). TPCK/TPACK research and development: Past, present, and future directions. Australasian Journal of Educational Technology, 33(3), i-viii. https://doi. org/10.14742/ajet.3907.

Harris, J., Grandgenett, N., \& Hofer, M. (2010). Testing a TPACK-based technology integration assessment rubric. In Society for Information Technology \& Teacher Education International Conference (pp. 38333840). Association for the Advancement of computing in education (AACE). https://www.learntechlib. org/primary/p/33978/.

Koehler, M. J., Mishra, P., \& Cain, W. (2013). What is technological pedagogical content (TPACK)? Journal of Education, 193(3), 13-19. https://doi.org/10.1177/002205741319300303.

Koehler, M. J., Mishra, P., Kereluik, K., Shin, T. S., \& Graham, C. R. (2014). The technological pedagogical content knowledge framework, In Handbook of research on educational communications and technology (pp. 101-111). New York, NY: Springer. https://doi.org/10.1007/978-1-4614-3185-5_9.

Koh, J., Chai, C. S., \& Tsai, C. C. (2010). Examining the technological pedagogical content knowledge of Singapore preservice teachers with a large-scale survey. Journal of Computer Assisted Learning, 26, 563573. https://doi.org/10.1111/j.1365-2729.2010.00372.x.

Kontkanen, S., Dillon, P., Valtonen, T., Renkola, S., Vesisenaho, M., \& Väisänen, P. (2016). Pre-service teachers' experiences of ICT in daily life and in educational contexts and their proto-technological pedagogical knowledge. Education and Information Technologies, 21(4), 919-943.

Lei, J. (2009). Digital natives as preservice teachers: What technology preparation is needed? Journal of Computing in Teacher Education, 25(3), 87-97. https://doi.org/10.1080/10402454.2009.10784615.

Mishra, P., \& Koehler, M. J. (2006). Technological pedagogical content knowledge: A framework for integrating technology in teacher knowledge. Teachers College Record, 108(6), 1017-1054 https://www.learntechlib.org/p/99246/.

Pamuk, S. (2011). Understanding pre-service teachers' technology use through TPACK framework. Journal of Computer Assisted Learning, 28(5), 425-439. https://doi.org/10.1111/j.1365-2729.2011.00447.x.

Patton, M. Q. (1999). Enhancing the quality and credibility of qualitative analysis. Health Services Research, 34(5 Pt 2), 1189. 
Petko, D., Prasse, D., \& Cantieni, A. (2018). The interplay of school readiness and teacher readiness for educational technology integration: A structural equation model. Computers in the Schools, 35(1), 1-18. https://doi.org/10.1080/07380569.2018.1428007.

Sadaf, A., Newby, T., \& Ertmer, P. (2012). Exploring pre-service teachers' beliefs about using web 2.0 technologies in K-12 classroom. Computers \& Education, 59(3), 937-945. https://doi.org/10.1016/j. compedu.2012.04.001.

Savenye, W. C., \& Robinson, R. S. (2005). Using qualitative research methods in higher education. Journal of Computing in Higher Education, 16(2), 65-95. https://doi.org/10.1007/BF02961475.

Shulman, L. (1986). Those who understand: Knowledge growth in teaching. Educational Researcher, 15(2), 4-14. https://doi.org/10.3102/0013189X015002004.

Shulman, L. (1987). Knowledge and teaching: Foundations of the new reform. Harvard Educational Review, 57(1), 1-21. https://doi.org/10.17763/haer.57.1.j463w79r56455411.

Teo, T., \& Milutinovic, V. (2015). Modelling the intention to use technology for teaching mathematics among pre-service teachers in Serbia. Australasian Journal of Educational Technology, 31(4). https://doi. org/10.14742/ajet.1668.

Tondeur, J., Van Braak, J., Sang, G., Voogt, J., Fisser, P., \& Ottenbreit-Leftwich, A. (2012). Preparing preservice teachers to integrate technology in education: A synthesis of qualitative evidence. Computers \& Education, 59(1), 134-144.

Tondeur, J., Kershaw, L., Vanderlinde, R. R., \& Van Braak, J. (2013). Getting inside the black box of technology integration in education: Teachers' stimulated recall of classroom observations. Australasian Journal of Educational Technology, 29(3).

Valtonen, T., Pöntinen, S., Kukkonen, J., Dillon, P., Väisänen, P., \& Hacklin, S. (2011). Confronting the technological pedagogical knowledge of Finnish net generation student teachers. Technology, Pedagogy and Education, 20(1), 1-16.

Valtonen, T., Kukkonen, J., Kontkanen, S., Mäkitalo-Siegl, K., \& Sointu, E. (2018). Differences in pre-service teachers' knowledge and readiness to use ICT in education. Journal of Computer Assisted Learning. 34(2), 174-182.

Willermark, S. (2018). Technological pedagogical and content knowledge: A review of empirical studies published from 2011 to 2016. Journal of Educational Computing Research, 56(3), 315-343. https://doi. org/10.1177/0735633117713114.

Publisher's note Springer Nature remains neutral with regard to jurisdictional claims in published maps and institutional affiliations.

\section{Affiliations}

\section{Teemu Valtonen ${ }^{1}$ • Ulla Leppänen ${ }^{1}$ • Mareena Hyypiä ${ }^{1}$ • Erkko Sointu ${ }^{1}$ • Anneke Smits $^{2} \cdot$ Jo Tondeur ${ }^{3}$}

\section{Erkko Sointu}

https://orcid.org/

\section{Anneke Smits}

https://orcid.org/

Jo Tondeur

https://orcid.org/

1 Faculty of Philosophy, University of Eastern Finland, Kuopio, Finland

2 Windesheim University of Applied Sciences, Zwolle, Netherlands

3 Vrije Universiteit Brussel, Ixelles, Belgium 